\title{
SELECTIVE CONTROL OF BARLEY GRASS IN PASTURE WITH A MIXTURE OF TCA AND 2,2-DPA
}

\author{
R. W. Moffat and B. N. MacDiarmid \\ Ivon Watkins-Dow Ltd., New Plymouth
}

\section{Summary}

Results of field trials and farmer usage of a proprietary mixture of TCA and 2,2-DPA for the selective control of barley grass (Hordeum murinum) in pasture are presented and discussed. The maximum degree of barley grass control commensurate with acceptable pasture tolerance was achieved with a single application during the June to late August period of $3.8 / 0.7 \mathrm{lb}$ of the TCA/2,2-DPA mixture in low rainfall areas and $5.1 / 0.9 \mathrm{lb}$ in higher rainfall areas or on dense barley grass stands. The combination gave more reliable and superior barley grass control than either TCA or 2.2-DPA applied alone.

\section{INTRODUCTION}

BARLEY GRASS (Hordeum murinum) is an annual grass weed which flourishes in a number of districts in New Zealand and has become a serious economic problem (Loughnan, 1964) In some districts, particularly on the more fertile improved pastures, its spread has been controlled to a certain extent by grazing management practices (Gunning, 1966). However, recent studies with the closely related species $H$. leporinum in Australia have shown that, in conditions similar to the east coast of New Zealand, grazing intensity has no effect on the number of seeds set, while high stocking rates can increase the viability of the seed (Smith, 1968). Thus, it is not surprising that, in many districts in New Zealand, grazing practices have not been sufficient to control barley grass adequately and herbicide treatments have been necessary.

A single treatment with TCA in the winter or split, foliar sprays of 2,2-DPA in the early spring have been the main herbicides used. Paraquat has also been recommended, but only as a spot application to barley grass when the seed-heads just appear, preferably as a follow-up to earlier sprayings with other herbicides (Thompson, 1964). Unfortunately, the specific conditions under which these herbicides perform satisfactorily are often too critical for the New Zealand farmer to fit into his normal farm operations. For example, 2,2-DPA can give acceptable barley grass control and pasture selectivity if applied at the correct time in the spring; but it can perform erratically if the barley grass is too rank (Merry, 1959). In addition, two spring treatments are usually required in the one season because of the negligible soil residual activity of 2,2-DPA to control lategerminating plants. By contrast, TCA can give acceptable residual control of both young plants and seedlings, provided the pasture is closely grazed at the time of application. The results are more variable if the barley grass plants are already well established, if the pasture is too long, or if TCA is applied outside the cool, mid-winter period (Collin, 1955). 


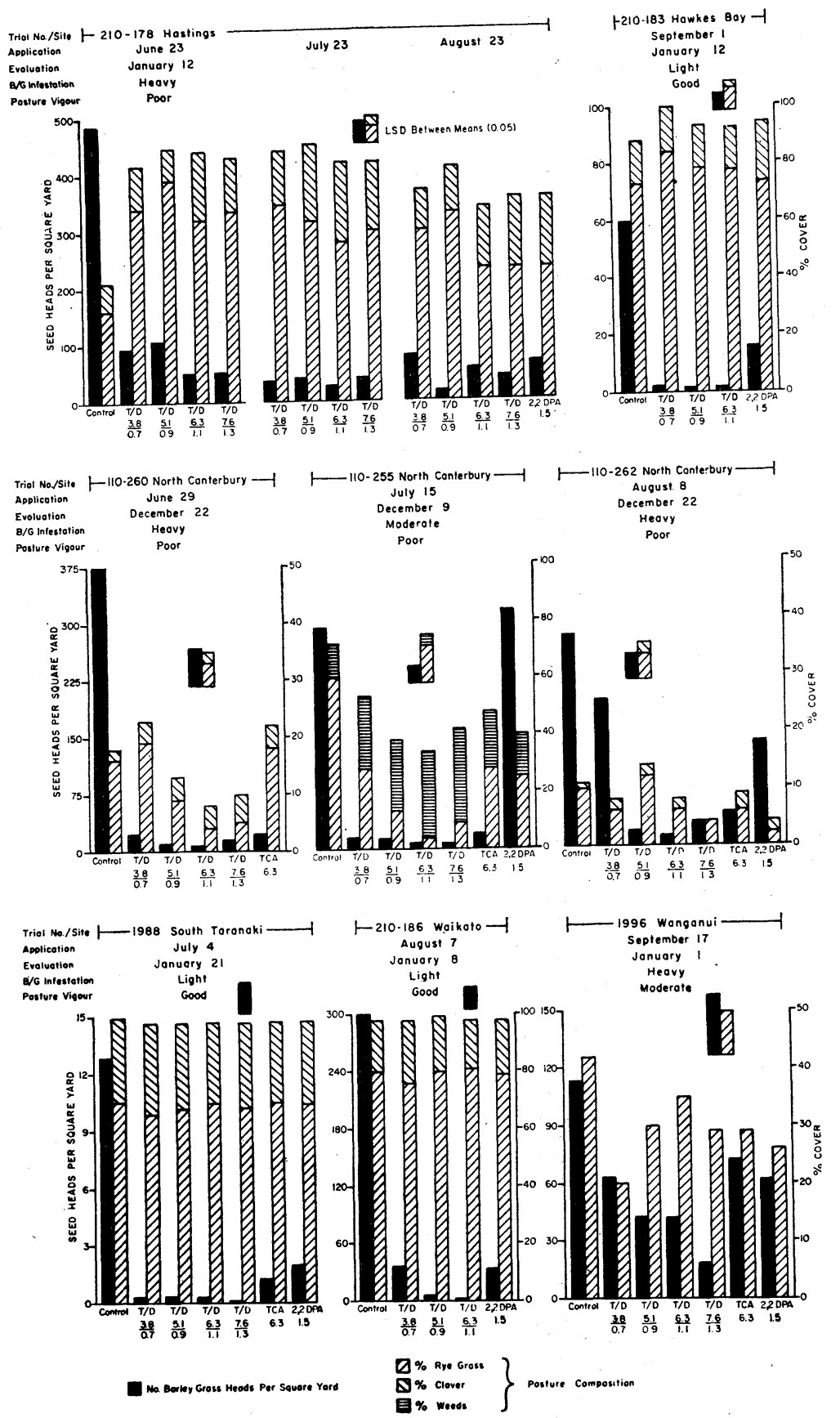

FIG. 1: Barley grass control and percentage pasture cover following treatmints with a TCA/2,2-DPA mixture $(T / D), T C A$ and 2,2-DPA.

(C) 1970 New Zealand Plant Protection Society (Inc.) www.nzpps.org Refer to http://www.nzpps.org/terms_of_use.html 
In an attempt to combine the attributes of both TCA and 2,2-DPA in a single treatment, a proprietary mixture of the two chemicals was formulated in 1968. During 1969, the Research Division of Ivon WatkinsDow Ltd. conducted trials throughout New Zealand to evaluate this product. The results of these trials, together with the results of its performance in commercial usage, are presented in this paper.

\section{EXPERIMENTAL}

Small-scale trials were laid with a plot size of $1 / 200$ acre and 3 or 4 replications. To investigate in detail the effect of the density of the barley grass infestation on herbicidal activity, one trial was laid with one replicate of treatments applied along a densely infested fenceline area, while the other was applied further into the paddock, where the infestation was considerably less dense. All treatments were applied with an Oxford precision sprayer using Tee Jet 730308 fan tips applying 20 to 30 gal of water per acre. Larger scale trials were also laid, with plots one boom width (18 ft $9 \mathrm{in}$.) wide, covering an area of $1 / 20$ to $1 / 15$ of an acre and replicated 2 or 3 times.

A proprietary mixture (T/D) containing $63 \% \mathrm{w} / \mathrm{w}$ TCA and $11 \% \mathrm{w} / \mathrm{w}$ 2,2-DPA was applied at $3.8 / 0.7 \mathrm{lb}, 5.1 / 0.9 \mathrm{lb}, 6.3 / 1.1 \mathrm{lb}, 7.6 / 1.3 \mathrm{lb}$ between June and September and its performance was compared with the recommended treatments of TCA at $6.3 \mathrm{lb}$ and 2,2-DPA at $1.5 \mathrm{lb}$. All rates of application are expressed in $1 \mathrm{~b}$ active ingredient per acre. To measure the degree of barley grass control, counts of seed-heads and seedlings were made in December or January when seed-heads were most prevalent. The number of seed-heads were counted in four $(2 \mathrm{ft} \times$ $2 \mathrm{ft})$ or two to four $(3 \mathrm{ft} \times 3 \mathrm{ft})$ quadrats placed at random in each plot. At the same time, visual assessments of the percentage cover of desirable pasture species (mainly ryegrass and clover), were made by two or more independent observers.

\section{RESULTS}

The results of field trials from four of the main barley grass districts in New Zealand are shown in Fig. 1. In the Hastings/Hawke's Bay trials (210-178 and 210-183) all treatments produced an $80 \%$ or greater reduction in the number of barley grass seed-heads. Although the T/D mixture caused some pasture damage under the cold, dry winter conditions (only a quarter of the average rainfall), the treated plots recovered well with good spring growing conditions. Only when it was applied in September was there no significant increase in the cover of desirable pasture species from all treatments.

In the North Canterbury trials, all rates of the T/D mixture except the 3.8/0.7 $\mathrm{lb}$ rate in August produced at least $90 \%$ control of barley grass. TCA at $6.3 \mathrm{lb}$ also produced good results. 2,2-DPA was less effective and less reliable than either of the other two chemicals. Although all rates of the T/D mixture produced acceptable barley grass control, the higher rates caused a considerable reduction in pasture cover, particularly when applied in June and July. This was the result of pasture damage which occurred during the cold, dry winter conditions, followed by failure of the pasture to recover during the unseasonally dry conditions in the spring. Consequently, where broadleaf weeds were present in poor pastures (trial 110-255) these increased as a result of reduced competition. The most effective treatment in North Canterbury commensurate with good pasture recovery was the June application of $T / D$ at $3.8 / 0.7 \mathrm{lb}$. 
When applied to the more fertile pastures in higher rainfall areas on the west coast of the North Island, both the July and August treatments (trials 1988 and 210-186) of the T/D mixture gave excellent barley grass control and pasture tolerance at all rates. Under these pasture growth conditions, the $5.1 / 0.9 \mathrm{lb}$ rate was the most acceptable treatment. Trial 1996 demonstrates the reduced barley grass control and increased pasture damage likely to occur by delaying the application until September, when spring pasture growth has commenced.

\section{Effect of Density of Infestation and Height of Pasture on HERBICIDAL ACTIVITY}

The number of seed-heads per square yard in each of the treatments for both the fenceline and paddock sites, are shown in Fig. 2. All rates of the T/D mixture and 2,2-DPA gave excellent control of barley grass in the paddock site. By contrast, in the fenceline site where the barley grass was higher and more dense, 2,2-DPA, all treatments of the T/D mixture at $3.8 / 0.7 \mathrm{lb}$, and the June treatment at $5.1 / 0.9 \mathrm{lb}$ gave significantly less control than the other treatments. The cover of desirable pasture species in all treatments (76 to $99 \%$ ) was significantly greater than in the untreated control $(43 \%)$. This trial illustrates not only the increased effectiveness of the T/D mixture compared with 2,2-DPA alone but also the necessity for increased rates of the T/D mixture in situations containing heavy barley grass infestations

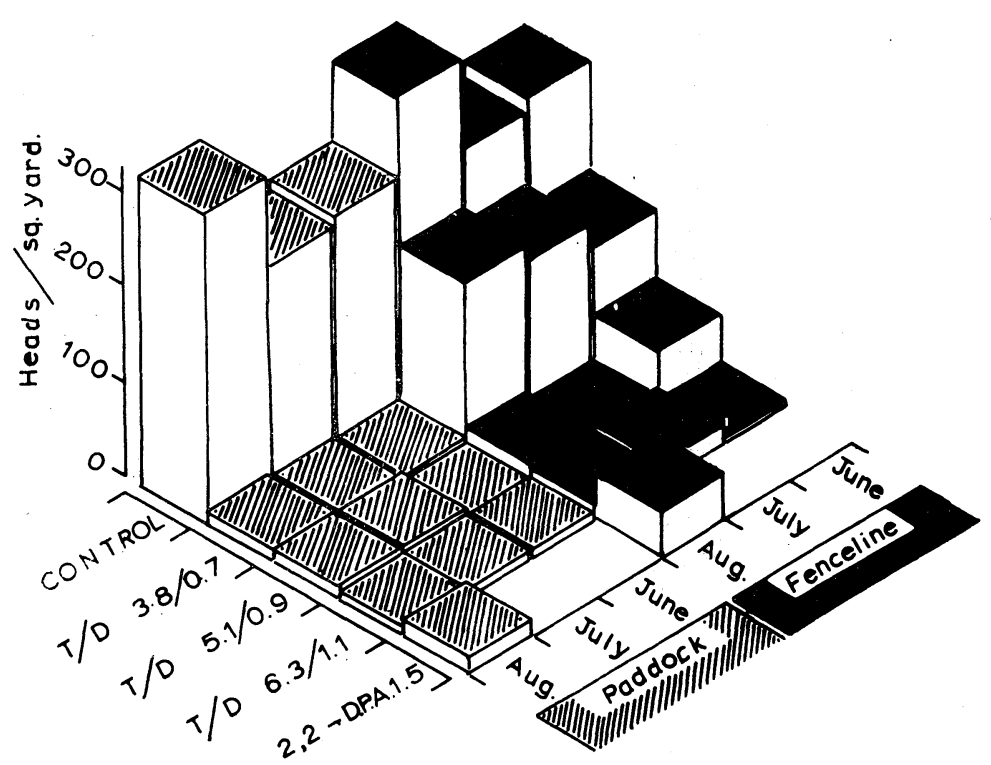

FIG. 2: Barley grass control using a TCA/2,2-DPA mixture $(T / D)$ and 2,2-DPA when applied to a fenceline and paddock site. 


\section{FARMER USAGE}

The T/D mixture was used by farmers in 17 different locations throughout New Zealand during 1969. Time of application ranged between July and September and varied from $4.4 / 0.8 \mathrm{lb}$ to $7.6 / 1.3 \mathrm{lb}$. The level of barley grass control was acceptable in all cases. The degree of pasture suppression was the most variable factor and depended mainly on the pasture growth conditions in the locality. Where the pasture was under severe moisture or cold stress, rates above $5.1 / 0.9 \mathrm{lb}$ gave unacceptable temporary pasture damage. Where the pasture was not closely grazed - e.g., dairy pastures - and normal, moist spring growth conditions occurred, 7.6/ $1.3 \mathrm{lb}$ could be used without any permanent damage to the desirable pasture species.

\section{DISCUSSION}

To be widely accepted on a farm scale, a herbicide for the selective control of barley grass in pasture must meet the following criteria:

(1) Reliably give a high level of control as a post-emergent treatment plus have some residual pre-emergent soil activity for seedling control.

(2) Have a high level of selectivity to those desirable pasture species which rapidly cover the ground following treatment, thereby reducing the chances of seedling weed reinfestation.

(3) Have a time of application which is not too critical and which preferably occurs when maximum advantage from the normal pattern of pasture growth may be obtained. The treatment should fit easily into the pattern of the farming operation.

(4) Be an economic treatment.

Of the three herbicides evaluated in the present series of trials, the T/D mixture most nearly satisfied the above criteria. The control of barley grass with the mixture was generally greater than $90 \%$ and was relatively independent of the rate applied.

On the other hand, pasture damage and subsequent pasture re-establishment in the treated areas varied according to the rate and time of application, the climatic conditions prior to and following treatment, the density of the barley grass infestation, and the vigour of the pasture sward. The maximum degree of barley grass control commensurate with acceptable pasture tolerance was, therefcre, obtained by applying the lowest rate $(3.8 / 0.7 \mathrm{lb})$ in the cool, low rainfall (less than $30 \mathrm{in}$. per year) east coast areas and applying the higher rate $(5.1 / 0.9 \mathrm{lb})$ in the more temperate, higher rainfall areas or on dense barley grass stands. The most desirable time of treatment was from June until late August.

It is important to note that in none of the treatments was all the barley grass prevented from seeding, nor were seedlings prevented from germinating late in the spring. Complete barley grass control may, therefore, only be achieved by a programme which incorporates repeat applications of the herbicide and the re-establishment of a competitive pasture sward. Trials are being conducted in the coming season to establish the most desirable programme to achieve this in the various districts. In addition, different formulations of the TCA/2,2-DPA mixture are being evaluated. 


\section{ACKNOWLEDGEMENTS}

The authcrs are indebted to the staff of the Research Division, Ivon Watkins-Dow Ltd., for carrying out the trial programme.

\section{REFERENCES}

Collin, F. H., 1955: Proc. 8th N.Z. Weed Control Conf.: 23.

Gunning, B. A., 1966: Proc. 19th N.Z. Weed \& Pest Control Conf.: 127.

Loughnan, R. J. M., 1964: Proc. 17th N.Z. Weed \& Pest Control Conf.: 40.

Merry, D. M. E., 1959: Proc. 12th N.Z. Weed Control Conf.: 77.

Smith, D. F., 1968: Aust. J. Exptl. Agric. \& Anim. Husb., 8 (4) : 706.

Thompson, F B., 1964: Proc. 17th N.Z. Weed \& Pest Control Conf.: 39. 